\section{Kompass \\ Nutrition \& Dietetics}

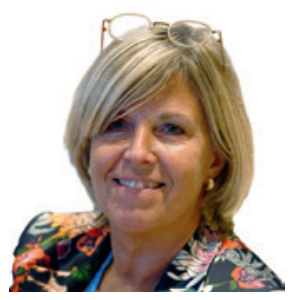

Annemieke van Ginkel-Res

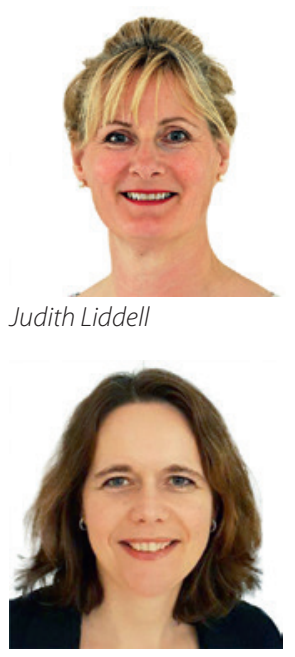

Elke Naumann

Dear reader,

We are really happy that the first issue of Kompass Nutrition \& Dietetics is now in front of you! The European Federation of the Associations of Dietitians (EFAD) has always hoped to start a dietetic journal to share dietetic knowledge and experience with dietitians throughout Europe. Every day, new knowledge and new experiences are identified in dietetics - in your own country and beyond. Applying knowledge to dietetic practice is key to our profession. Every day, new scientific information is published, requiring dietitians to translate this information into practice. Kompass Nutrition \& Dietetics aims to bridge this gap between science and dietetic practice. It will enable dietitians to learn about new insights, new methods and new ways of working that exist in Europe. We hope that this information will inspire you to further improve our profession.

\title{
A Bridge between International Science and Dietetic Practice
}

\author{
Annemieke van Ginkel-Res ${ }^{a}$ Judith Liddell ${ }^{b}$ Elke Naumann ${ }^{c}$ \\ ${ }^{a}$ Honorary President of EFAD, Naarden, The Netherlands; ${ }^{b}$ Executive Director of EFAD, \\ Naarden, The Netherlands; ${ }^{C}$ Coordinator of EFAD Journal of Nutrition and Dietetics, Naarden, \\ The Netherlands
}

It took some time for EFAD to find out what kind of dietetic journal would best fit our members. To start to shape the new journal, we consulted national dietetic associations and the editors of their national journals, and we consulted EFAD's European Specialist Dietetic Networks. We then started working in a small Task and Finish Group and had our first meetings with Karger. Increasingly, we believed that a Kompass Nutrition \& Dietetics would be the perfect journal for EFAD. Dr. Liana Poulia, one of the members of the Task and Finish Group, volunteered to be the editor of the first issue.

Each issue of Kompass Nutrition \& Dietetics will focus on a specific dietetic topic. The journal will start with two issues per year and contain different types of articles, including knowledge transfer articles, explaining how outcomes of scientific research could be used in dietetic practice. Experts from inside and outside EFAD will be asked to write these knowledge transfer articles. It will also include reviews and case reports, which could be translated articles from journals of national dietetic associations. Please let us know if you have articles that you wish to share across Europe!

The publication of Kompass Nutrition \& Dietetics is a new venture for EFAD, so please feel free to think with us and provide feedback (secretariat@efad.org).

We hope that you, as members of EFAD's member associations, will appreciate Kompass Nutrition \& Dietetics. Enjoy reading!

ב The European Federation of LDe Associations of Dietitians

THE VOICE OF EUROPEAN DIETETICS
The European Federation of the Associations of Dietitians (EFAD) Gooimeer 4-15

1411 DC Naarden, The Netherlands secretariat@efad.org www.efad.org 